Proc. Indian Acad. Sci. (Chem. Sci.), Vol. 89, Number 2, April 1980, pp. 201-207. (C) Printed in India.

\title{
Vibrational spectra and thermodynamic functions of allyl acetate
}

\author{
BHADUR SINGH, R PRASAD* and R M P JAISWAL \\ Department of Physics, Kurukshetra University, Kurukshetra 132 119, India \\ *Department of Chemistry, Regional Engineering College, Kurukshetra 132 119, India \\ MS received 6 June 1979; revised 7 December 1979
}

\begin{abstract}
Raman spectrum of allyl acetate molecule has been photographed in liquid phase using $4358 \AA$ line of mercury arc as the exciting line. Infrared absorption spectrum of the molecule has been recorded in liquid phase in the frequency range $200-4000 \mathrm{~cm}^{-1}$. Both the spectra have been analysed to identify the fundamental frequencies. Assuming $C_{2}$ symmetry, the observed fundamental frequencies have been assigned to various modes of vibration and compared with the frequencies of allyl halides and acetic acid. On the basis of present assignments of fundamental vibrational frequencies and assumed approximate structural parameters of the molecule, thermodynamic functions have been computed.
\end{abstract}

Keywords. Vibrational spectra; thermodynamic functions; allyl acetate.

\section{Introduction}

The vibrational spectra of propene $\left(\mathrm{CH}_{2}=\mathrm{CH}-\mathrm{CH}_{3}\right)$ molecule have been studied in detail by several workers using infrared and Raman methods (Herzberg 1945; Herschbach 1962; Lin and Swalen 1959; Silvi et al 1973). Fateley and Miller (1963) studied the torsional vibration of this molecule in the far infrared. Recently, vibrational spectra and normal coordinate analysis of four isotopic species of propene have appeared in literature (Silvi et al 1973). The microwave spectrum of the above molecule has been studied and structure parameters determined (David and Mann 1957; Herschbach and Krisher 1958). Among the substituted propene molecules the infrared, Raman as well as microwave spectra of a large number of compounds have been studied in recent years (Gunde and Azman 1.975; Hirota 1965; Mclachlan and Nyquist 1968; Siegel 1957; Torgrimsen and Klaboe 1974). It has also been established from these studies that allylic compounds substituted in the 3-position $\left(\mathrm{CH}_{2}=\mathrm{CH}-\mathrm{CH}_{2} \mathrm{X}\right.$, where $\mathrm{X}=\mathrm{F}, \mathrm{Cl}, \mathrm{Br}, \mathrm{I}, \mathrm{CN}, \mathrm{NH}_{2}, \mathrm{OH}, \mathrm{SH}$, NCO and NCS) have cis and gauche conformations (Torgrimsen and Klaboe 1974 and references therein). By using the proton magnetic resonance method to study rotational isomerism Bothner-By and his coworkers (Bothner-By and Naar-Colin 1961; Bothner-By and Gunter 1962; Bothner-By et al 1962) have shown that when the size of the substituent in the 3-carbon position is increased, the 
population of the cis form decreases perhaps due to the steric repulsion between the substituent and the $=\mathrm{CH}_{2}$ group (Hirota 1965). However, a detailed study of vibrational spectra of allyl acetate $\left(\mathrm{CH}_{2}=\mathrm{CH}-\mathrm{CH}_{2} \mathrm{OCOCH}_{3}\right)$ is not available in literature, although its infrared spectrum has been reported briefly by Nakanishi (1966). The present work comprises the detailed study of vibrational spectra of allyl acetate molecule in liquid phase both by Raman and infrared methods to identify the fundamental frequencies. This gives evidence of the presence of only one rotamer in liquid phase as the infrared and Raman bands do not show any splitting and the number of identified fundamental frequencies is just as expected. Thus gauche structure closer to the planar trans conformation of the molecule as in figure 1 has been assumed for simplicity. On this basis the frequencies have been assigned to various modes of vibration of the molecule and its thermodynamic properties computed statistically on a TDC-316 computer using the assigned frequencies.

\section{Experimental details}

Chemically pure allyl acetate obtained from A G Fluka, Switzerland, was used. The compound was used for resording Raman spectrum only after twice distillation under vacuum. The Raman spectrum was recorded on a Russian ESP-51 constant deviation glass spectrograph with a linear dispersion of $19 \AA / \mathrm{mm}$ at $4000 \AA$. An evacuated $6 \mathrm{cc}$ Raman cell was filled with fresh compound and then sealed. A low pressure mercury arc running at 230 volts ac and $3 \mathrm{amp}$ served as the source of excitation. Raman cell and the $\mathbf{H g}$-arc were put along two focal axes of an ellipsoidal mirror reflector forming the inner surface of a double-walled housing through which continuous water circulation was maintained to avoid extra heating. The $4358 \AA$ line of $\mathrm{Hg}$-arc was isolated with $\mathrm{NaNO}_{2}$ solution filter. The exposures varied between 15 and $30 \mathrm{hr}$ with a slit width of $40 \mu$. The ORWO-27 cut films were used to photograph the spectrum. Measurements were made on a comparator (Optical Instruments, New Delhi) with a least count of $0.0001 \mathrm{~cm}$ and accurate to within $\pm 3 \mathrm{~cm}^{-1}$ for strong lines and $\pm 8 \mathrm{~cm}^{-1}$ for weak lines. Infrared spectrum of the compound was recorded in the liquid phase on a PerkinElmer 621 double-beam grating infrared spectrophotometer using a cell of thickness $0.05 \mathrm{~mm}$. The wave numbers are noted at peak absorption positions of the bands.

\section{Results and discussion}

Table 1 shows comparison of the fundamental frequencies identified in the spectra of the molesule with those of allyl bromide and acetic acid molecules.

With assumed structure and approximate bond lengths and bond angles of figure 1 allyl acetate molecule possesses the plane of the molecule as the only symmetry element in which lie 11 atoms including 5 carbon, 2 oxygen and 4 hydrogen. Two pairs of hydrogen atoms each attached at $C_{3}$ and $C_{5}$ carbon atoms are situated symmetrically above and below the plane of symmetry. As such the molecule belongs to $C_{s}$ point group and has a total of 39 vibrational frequencies including 14 stretching, 20 angle deformation and 5 torsional frequencies. It is also worked out that 25 of these frequencies belong to in-plane 
$\left(a^{\prime}\right)$ and 14 of them to out -of-plane $\left(a^{\prime \prime}\right)$ vibrational modes. Both these types of vibrations are infrared as well as Raman astive. While totally symmetric planar vibrations should be polarised in the Raman spectrum, the non-totally symmetric non-planar ones are depolarised. The polarisation measurements, however, could not be made as very long exposures were required in the present experimental set-up.

Considering allyl acetate molecule as a mono-substituted propene on position-3 on the one hand and a substituted acetic acid replacing $\mathrm{H}$ atom of the $\mathrm{OH}$ group by the allyl group on the other, observed fundamental frequencies can be grouped as (i) allyl group frequencies and (ii) acetate group frequencies. These two groups of frequencies are discussed separately as follows:

\subsection{Allyl group frequencies}

As the allyl group consists of one pair of hydrogen atoms attached to the first carbon atom, one hydrogen atom attached to the second carbon atom and another pair of hydrogen atoms attashed to the third carbon atom, we expect one $=\mathrm{CH}_{2}$ asymmetric stretching, one $=\mathrm{CH}_{2}$ symmetric stretching, one $\mathrm{CH}$ stretching, one methylene $\mathrm{CH}_{2}$ asymmetric stretching and one methylene $\mathrm{CH}_{2}$ symmetric stretching frequencies in the region $2950-3100 \mathrm{~cm}^{-1}$. Assignments of suitable frequencies to the above modes of vibration of molecule have been made by comparison with similar assignments in other mono-substituted propenes as shown in table 1. For the remaining two aliphatic $\mathrm{C}=\mathrm{C}$ stretching and $\mathrm{C}-\mathrm{C}$ stretching modes frequencies around 1650 and $931 \mathrm{~cm}^{-1}$ respectively have been assigned. One of the frequencies of propene molecule associated with stretching of $\mathrm{CH}$ bond which has been replaced by $\mathrm{CO}$ bond in the present molecule will correspond to a non-totally symmetric $\left(a^{\prime \prime}\right)$ twisting mode of vibration. A weak Raman fundamental at $293 \mathrm{~cm}^{-1}$ has been assigned to this mode. Similarly, frequencies for angle deformation and other torsional modes have been assigned by comparison with their counterparts in mono-substituted propenes (McLachlan and Nyquist 1968; Torgrimsen and Klaboe 1974).

\subsection{Acetate group frequencies}

Considering allyl group as a single unit $\mathrm{Y}, \mathrm{CH}_{3} \mathrm{COOY}\left(\mathrm{Y}=\mathrm{C}_{3} \mathrm{H}_{5}\right)$ molecule will possess two $\mathrm{CH}_{3}$ asymmetric stretching, one $\mathrm{CH}_{3}$ symmetric stretching, one $\mathrm{C}=\mathrm{O}$ stretching, one $\mathrm{C}-\mathrm{C}$ stretching, one $\mathrm{C}-\mathrm{O}$ stretching and one $\mathrm{O}-\mathrm{C}$ stretching vibrations. Suitable fundamental frequencies have been assigned to the first six stretching modes of vibration by comparison with their assignments in acetic acid molecule (Fukushima and Zwolinski 1969; Wilmshurst 1956). A very strong fundamental observed in the Raman spectrum at $783 \mathrm{~cm}^{-1}$ has been assigned to the $\mathrm{O}-\mathrm{C}$ stretching vibration. Assignments of the frequencies to the angle deformation modes compare well with their counterparts in acetic acid molecule in table 1. Assignment of a frequency around $433 \mathrm{~cm}^{-1}$ to $\mathrm{O}-\mathrm{COCH}_{3}$ torsional vibration is, however, tentative. The corresponding frequency in formic acid has been observed by Millikan and Pitzer (1957) at $636 \mathrm{~cm}^{-1}$. On substitution of allyl group in acetic acid the $\mathrm{C}-\mathrm{O}-\mathrm{H}$ bent mode is replaced by the $\mathrm{C}-\mathrm{O}-\mathrm{C}$ deformation mode. So we expect much reduction in the corresponding frequency in the present molecule as 
Table 1. Correlation of fundamental frequencies (in $\mathrm{cm}^{-1}$ ) of allyl acetate with those of allyl bromide and acetic acid.

\begin{tabular}{|c|c|c|c|c|c|}
\hline \multirow{2}{*}{$\begin{array}{c}\text { Symmetry } \\
C_{s}\end{array}$} & \multirow[b]{2}{*}{$\begin{array}{c}\text { Allyl bromide } \\
\text { (Mc Lachlan } \\
\text { and Nyquist } \\
\text { 1968) }\end{array}$} & \multirow[b]{2}{*}{$\begin{array}{c}\text { Acetic acid } \\
\text { (Wilmshurst } \\
\text { 1956) }\end{array}$} & \multicolumn{2}{|c|}{ Allyl acetate } & \multirow{2}{*}{ Assignment } \\
\hline & & & $\begin{array}{l}\text { Infrared } \\
\text { spectrum }\end{array}$ & $\begin{array}{l}\text { Raman } \\
\text { spectrum }\end{array}$ & \\
\hline$a^{\prime}$ & 3093 & & $3098(\mathrm{~m})$ & $3100(\mathrm{vwb})$ & $v\left(=\mathrm{CH}_{2}\right)$ asym. \\
\hline$a^{\prime \prime}$ & . & 3048 & 3030 (sh) & & $v\left(\mathrm{CH}_{3}\right)$ asym. \\
\hline$a^{\prime}$ & 3022 & .. & & $2995(w)$ & $\nu\left(=\mathrm{CH}_{2}\right) \mathrm{sym}$ \\
\hline$a^{\prime \prime}$ & 2986 & .. & $2983(\mathrm{sh})$ & .. & $v\left(\mathrm{CH}_{2}\right)$ asym. \\
\hline$a^{\prime}$ & 2986 & & $2983(\mathrm{sh})$ & .. & $v(\mathrm{CH})$ \\
\hline$a^{\prime}$ & .. & 2947 & 2983 (sh) &.. & $v\left(\mathrm{CH}_{3}\right)$ asym. \\
\hline$a^{\prime}$ & 2968 & .. & 2938 (vs) & $2947(s)$ & $v\left(\mathrm{CH}_{2}\right) \mathrm{sym}$ \\
\hline$a^{\prime}$ & .. & 2961 & 2938 (vs) & $2947(s)$ & $v\left(\mathrm{CH}_{3}\right) \mathrm{sym}$. \\
\hline$a^{\prime}$ & & 1799. & 1723 (vs) & $1743(\mathrm{~m})$ & $v(\mathrm{C}=0)$ \\
\hline \multirow[t]{2}{*}{$a^{\prime}$} & 1638 & & & & \\
\hline & $1647^{*}$ & .. & $1643(\mathrm{~m})$ & 1658 (vs) & $v(\mathrm{C}=\mathrm{C})$ \\
\hline$a^{\prime \prime}$ & .. & 1445 & $1436(\mathrm{vs})$ & $1470(\mathrm{vvw})$ & $v\left(\mathrm{CH}_{3}\right)$ asym. \\
\hline$a^{\prime}$ & 1442 & .. & 1423 (vs) & $1430(\mathrm{mb})$ & $\left(\mathrm{CH}_{2}\right)$ scissoring \\
\hline$a^{\prime}$ & .. & 1401 & $1408(v s)$ & .. & $\beta\left(\mathrm{CH}_{3}\right)$ asym. \\
\hline$a^{\prime}$ & 1409 & .. & 1361 (vs) & $1361(v w b)$ & $=\mathrm{CH}_{2}$ scissoring \\
\hline$a^{\prime}$ & .. & 1340 & .. & $1336(w)$ & $\beta\left(\mathrm{CH}_{3}\right)$ sym. \\
\hline$a^{\prime}$ & .. & 1279 & . & $1297(\mathrm{sb})$ & $v(\mathbf{C}-0)$ \\
\hline$a^{\prime}$ & 1294 & $\ldots$ & $1250(\mathrm{sh})$ & $1259(\mathrm{mw})$ & $\beta(\mathrm{C}-\mathrm{H})$ \\
\hline \multirow[t]{2}{*}{$a^{\prime}$} & 1208 & & & & \\
\hline & $1245^{*}$ & .. & $1210(\mathrm{vs})$ & $1191(\mathrm{vw})$ & $\mathrm{CH}_{2}$ wagging \\
\hline \multirow[t]{2}{*}{$a^{\prime}$} & 1195 & & & & \\
\hline & $1042 *$ & .. & 1086 (vs) & $\cdots$ & $=\mathrm{CH}_{2}$ rocking \\
\hline \multirow[t]{2}{*}{$a^{\prime \prime}$} & 1071 & & & & \\
\hline & $1154^{*}$ &.. & $11.53(\mathrm{sh})$ & & $\mathrm{CH}_{2}$ twisting \\
\hline$a^{\prime \prime}$ & .. & 1068 & 1015 (vvs) & $1033(w)$ & $\mathrm{CH}_{\mathrm{a}}$ rocking \\
\hline$a^{\prime}$ & .. & 990 & 989 (vvs) & $979(\mathrm{vw})$ & $\mathrm{CH}_{3}$ rocking \\
\hline$a^{\prime \prime}$ & 984 & .. & 989 (vvs) & $979(\mathrm{vw})$ & $\phi\left(=\mathrm{CH}_{2}\right)$ \\
\hline$a^{\prime}$ & 935 & .. & 931 (vvs) & 931 (vw) & $v(\mathrm{C}-\mathrm{C})$ \\
\hline$a^{\prime \prime}$ & 926 & .. & $901(\mathrm{sh})$ & $890(w)$ & $=\mathrm{CH}_{2}$ wagging \\
\hline$a^{\prime}$ & .. & 846 & 833 (ms) & $836(s)$ & $v(\mathrm{C}-\mathrm{C})$ \\
\hline$a^{\prime}$ & $\therefore$ & . & .. & 783 (vs) & $v(\mathrm{O}-\mathrm{C})$ \\
\hline$a^{\prime}$ & .. & 1192 & .. & 744 (vvw) & $a(C-O-C)$ \\
\hline$a^{\prime \prime}$ & 866 & .. & 759 (vvwb) & 744 (vvw) & $\mathrm{CH}_{2}$ rocking \\
\hline$a^{\prime}$ & .. & 654 & $651(\mathrm{sh})$ & .. & $a(O=C-0)$ \\
\hline$a^{\prime \prime}$ & .. & 582 & $611(\mathrm{~s})$ & $623(v w)$ & $\mathrm{CO}_{2}$ wagging \\
\hline$a^{\prime}$ & .. & 536 & $554(\mathrm{~m})$ & $558(\mathrm{vvw})$ & $\mathrm{CO}_{2}$ rocking \\
\hline$a^{\prime \prime}$ & $575^{(a)}$ & .. & $575(\mathrm{sh})$ & .. & $\gamma(\mathbf{C}-\mathrm{H})$ \\
\hline$a^{\prime \prime}$ & .. & $636^{(b)}$ & $430(\mathrm{rvw})$ & $433(\mathrm{vw})$ & $\phi\left(\mathrm{O}-\mathrm{COCH}_{3}\right)$ \\
\hline \multirow[t]{2}{*}{$a^{\prime}$} & 392 & & & & \\
\hline & $458^{*}$ & .. & $342(\mathrm{~m})$ & $341(\mathrm{vw})$ & skeletal bending \\
\hline \multirow{2}{*}{$a^{\prime}$} & $\ddot{254}$ & .. & $291(v w)$ & $293(\mathrm{vw})$ & $\phi\left(\mathrm{C}-\mathrm{OCOCH}_{3}\right)$ \\
\hline & $215^{*}$ & & .. & $191(v w)$ & skeletal bending \\
\hline$a^{\prime \prime}$ & $119 *$ & .. & $\ldots$ & $146(v v w)$ & $\phi\left(\mathrm{CH}_{\mathbf{2}} \mathrm{X}\right)$ \\
\hline$a^{*}$ & .. & $93^{(c)}$ & .. & $95(\mathrm{vw})$ & $\phi\left(\mathrm{CH}_{3}\right)$ \\
\hline
\end{tabular}

Note: Explanation of footnotes is given in p. 207. 
shown in table 1. Although Fateley and Miller (1961) have observed a fundamental in the vapour phase of asetic acid at $130 \mathrm{~cm}^{-1}$ and have assigned the same to $\mathrm{C}-\mathrm{CH}_{3}$ torsional vibration, more recent values recommended for this mode by Fukushima and Zwolinski (1969), Shimanouchi (1972) and Chao et al (1978) are as 101,93 and $75 \mathrm{~cm}^{-1}$ respestively. On the other hand the $\mathrm{C}-\mathrm{CH}_{3}$ torsional frequency assigned in the propene molecule is at $188 \mathrm{~cm}^{-1}$ (in gas, Silvi et al 1973) and $177 \mathrm{~cm}^{-1}$ (in liquid, Herzberg 1945). In halogenated propenes the frequencies in the range 163-107 $\mathrm{cm}^{-1}$ (McLachlan and Nyquist 1968) have been assigned to $\mathrm{C}-\mathrm{CH}_{2} \mathrm{X}$ (where $\mathrm{X}=\mathrm{F}, \mathrm{Cl}, \mathrm{Br}$ and $\mathrm{I}$ ) torsional mode. In view of the above two frequencies observed in Raman spectrum of allyl acetate at 146 and $95 \mathrm{~cm}^{-1}$ in the present study could be assigned to $\mathrm{C}-\mathrm{CH}_{2} \mathrm{X}$ (where $\mathrm{X}=\mathrm{OCOCH}$ ) torsion and $\mathrm{C}-\mathrm{CH}_{3}$ torsion modes respectively.

\section{Thermodynamic properties}

Thermodynamic functions of the allyl acetate molecule have been calculated by utilising standard expressions (Herzberg 1945; Colthup 1964; Pitzer and Gwinn 1942) and the assigned fundamental frequencies of table 1. In order to determine rotational contribution, we make use of the assumed approximate structural parameters of the molecule as given in the figure on the basis of the microwave spectral studies of propene and acetic acid molecules by David and Mann (1957) and Tabor (1957) respectively. This molecule possesses five torsional frequencies in all but the barrier height $V_{0}$ for each of the four internal rotations excepting the one around $\mathrm{C}-\mathrm{CH}_{3}$ bond is very large as calculated in the harmonic approximation using the relationship (Miller et al 1967)

$$
v_{t}=\sigma_{i}\left(V_{0} F\right)^{1 / 2}
$$

where $F=h / 8 \pi^{2} c I_{m}$ in $\mathrm{cm}^{-1}, v_{t}$ is the observed torsional frequency in the respective internal rotation mode and $\sigma_{i}$ is the number of potential minima per revolution; also the symmetry number of the internal rotation and $I_{m}$ the reduced moment of

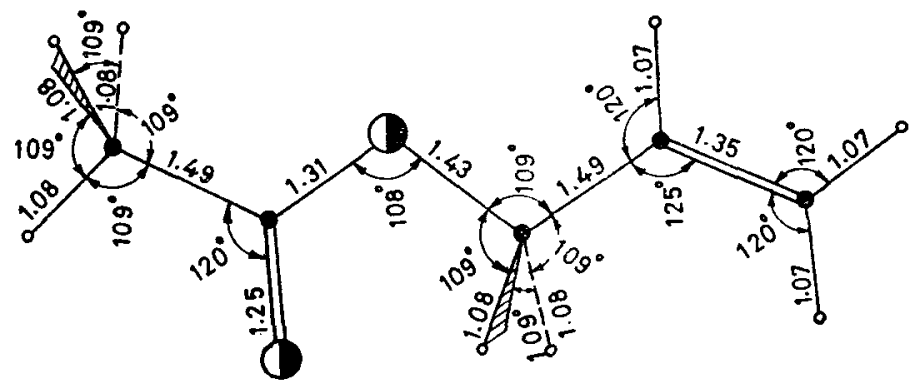
( oxygen
- Carbon
- Hydrogen

Figure 1. Structural parameters for allyl acetate (scale: $2 \cdot 54$ metres $=100 \AA$ ) 
inertia of the rotating top. Thus for the purpose of computing the contributions of internal rotations to the partition function all the four torsional frequencies for which barriers hindering internal rotations are very high have been taken as ordinary vibrations (Herzberg 1945), In $\mathrm{C}_{-} \mathrm{CH}_{3}$ torsion the rotational constant has been calculated as $5.6330 \mathrm{~cm}^{-1}$. With this value of $F, 95 \mathrm{~cm}^{-1}$ for $v_{i}$ and 3 for $\sigma_{i}$ equation (1) has been used to find the barrier height hindering internal rotation $V_{0}$ as $509 \mathrm{cal} / \mathrm{mole}$ which is an intermediate value. Hence, for computing the contribution of this mode to the various thermodynamic functions it has been omi ted from the list of ordinary vibrations and instead appropriate corrections have been made using Pitzer and Gwinn's (1942) table with the knowledge of an additional factor $Q_{f}$, appearing with overall rotational partition function in completely free internal rotation, which is given as (Herzberg 1945)

$$
Q_{s}=\left(8 \pi^{3} I_{m} k T\right)^{1 / 2} / \sigma_{i} h
$$

where symbols have their usual meanings.

The symmetry number for overall rotation is taken as 1 . The principal moments of inertia are calculated as $66 \cdot 6041,74 \cdot 6276,9 \cdot 0583$ and the reduced moment of inertia as 0.4965 in units of $10^{-39} \mathrm{gcm}^{2}$. The calculation of total contribution of $\left(H^{0}-H_{0}^{0}\right) / T,-\left(G^{0}-H_{0}^{0}\right) / T, S^{0}$ and $C_{p}^{0}$ at various temperatures $\left(100-1500^{\circ} \mathrm{K}\right)$ were carried out in the rigid rotor harmonic oscillator approximation and these relate to 1 mole of perfect gas at 1 atmosphere and are tabulated in table 2 . The computations have been done on a TDC-316 Computer. However, the experimental values for these functions in the present molecule are not available in literature and hence no comparison could be made.

Table 2. Thermodynamic functions (in cal ${ }^{\circ} \mathrm{K}^{-1}$ mole ${ }^{-1}$ ) of allyl acetate.

\begin{tabular}{lllll}
\hline $\begin{array}{c}\text { Temperature } \\
\left({ }^{0} \mathbf{K}\right)\end{array}$ & $\frac{\left(H^{0}-H_{0}^{0}\right)}{T}$ & $\frac{-\left(G^{0}-H_{0}^{0}\right)}{T} S^{0}$ & $C_{p}^{0}$ \\
& & & & \\
\hline & & & & \\
100 & $10 \cdot 27$ & $51 \cdot 94$ & $62 \cdot 21$ & $13 \cdot 29$ \\
200 & $13 \cdot 34$ & $62 \cdot 99$ & $73 \cdot 33$ & $19 \cdot 98$ \\
$273 \cdot 15$ & $15 \cdot 91$ & $64 \cdot 55$ & $80 \cdot 46$ & $26 \cdot 06$ \\
$298 \cdot 15$ & $16 \cdot 88$ & $65 \cdot 97$ & $82 \cdot 85$ & $28 \cdot 22$ \\
300 & $16 \cdot 95$ & $66 \cdot 08$ & $83 \cdot 03$ & $28 \cdot 38$ \\
400 & $20 \cdot 81$ & $71 \cdot 48$ & $91 \cdot 28$ & $36 \cdot 47$ \\
500 & $24 \cdot 65$ & $76 \cdot 54$ & $101 \cdot 20$ & $43 \cdot 32$ \\
600 & $28 \cdot 26$ & $81 \cdot 35$ & $109 \cdot 61$ & 48.92 \\
700 & $31 \cdot 55$ & $85 \cdot 95$ & $117 \cdot 51$ & $53 \cdot 53$ \\
800 & $34 \cdot 64$ & $90 \cdot 38$ & $125 \cdot 02$ & $57 \cdot 38$ \\
900 & $37 \cdot 27$ & $94 \cdot 60$ & $131 \cdot 87$ & $60 \cdot 63$ \\
1000 & $39 \cdot 75$ & $98 \cdot 65$ & $138 \cdot 41$ & $63 \cdot 41$ \\
1100 & $42 \cdot 00$ & $102 \cdot 56$ & $144 \cdot 56$ & $65 \cdot 78$ \\
1200 & 44.07 & $106 \cdot 30$ & $150 \cdot 37$ & $67 \cdot 82$ \\
1300 & $45 \cdot 98$ & $109 \cdot 90$ & $155 \cdot 88$ & $69 \cdot 58$ \\
1400 & $47 \cdot 71$ & $113 \cdot 38$ & $161 \cdot 09$ & $71 \cdot 11$ \\
1500 & $49 \cdot 28$ & $116 \cdot 72$ & $165 \cdot 99$ & $72 \cdot 43$ \\
& & & & \\
\hline
\end{tabular}




\section{Acknowledgement}

Authors are thankful to Professor N Nath for his keen interest in the present work. One of the authors (BS) is thankful to the Council of Scientific and Industrial Research, New Delhi, for financial assistance.

\section{References}

Bothner-By A A and Naar-Colin C $1961 \mathrm{~J}$. Am. Chem. Soc. 83231

Bothner-By A A, Naar-Colin C and Gunter H $1962 \mathrm{~J}$. Am. Chem. Soc. 842748

Bothner-By A A and Gunter 1962 Disc. Faraday Soc. 34127

Chao J and Zwolinski B J 1978 J. Phys. Chem. 7363

Colthup N B 1964 Introduction to infrared and Raman spectroscopy (New York : Academic Press)

David R L and Mann D E 1967 J. Chem. Phys. 27868

Fateley W G and Miller F A 1961 Spectrochim. Acta 17857

Fateley W G and Miller F A 1963 Spectrochim. Acta 19611

Fukushima K and Zwolinski B J 1969 J. Chem. Phys. 50737

Gunde R and Azman A 1975 J. Mol. Struct. 27212

Herzberg G 1945 Molecular spectra and molecular structure. Infrared and Raman spectra of polyatomic molecules (New York: Van Nostrand)

Herschbach D R 1962 Symposium on molecular structure and spectroscopy (Science Council of Japan, Tokyo) C 401

Herschbach D R and Krisher L C 1958 J. Chem. Phys. 28728

Hirota E 1965 J. Chem. Phys. 422071

Lin C C and Swalen J D 1959 Rev. Mod. Phys. 31841

McLachlan R D and Nyquist R A 1968 Spectrochim. Acta A24 103

Miller F A, Fateley W G and Witkowski R E 1967 Spectrochim. Acta A23 891

Millikan R C and Pitzer K S 1957 J. Chem. Phys. 271305

Nakanishi K 1966 Infrared absorption spectroscopy practical (San Francisco : Holden Day and Tokyo : Naukodo Co.)

Pitzer K S and Gwinn W D 1942 J. Chem. Phys. 10428

Shimanouchi 1972 Recommendation tables of molecular vibrational frequencies consolidated NSRDSNBS 39, U.S. Govt. Printing Press, Washington D.C., Vol. 1

Siegel S 1957 J. Chem. Phys. 27989

Silvi B, Labarbe P and Perchard J P 1973 Spectrochim. Acta A29 263

Tabor W J 1957 J. Chem. Phys. 251171

Torgrimsen T and Klaboe P 1974 J. Mol. Struct. 20 213, 229

Wilmshurst J K 1956 J. Chem. Phys. 251171

\section{Footnotes}

* Bands assigned to cis isomer

$\mathrm{X}=\mathbf{O C O C H}_{3}$.

$\mathrm{s}=$ strong, $\mathrm{vs}=$ very strong, $\mathrm{vvs}=$ very very strong, $\mathrm{m}=$ medium, $\mathrm{mw}=$ medium weak,

$\mathrm{w}=$ weak, $\mathrm{vw}=$ very weak, $\mathrm{vvw}=$ very very weak and $\mathrm{b}=$ broad.

$v=$ stretching, $\alpha=$ angle deformation, $\beta=$ in-plane bending, $\gamma=$ out-of-plane bending and $\phi=$ torsional deformation.

(a) Value in agreement with that of Silvi et al (1973).

${ }^{(b)}$ Millikan and Pitzer (1957) and ${ }^{(0)}$ Shimanouchi (1972). 